\title{
Ethoxylated Polyethylenimine Gel-Coated on Textile-Grade Acrylic Fiber. A Thermally Regenerable Superfast Sorbent for Water Desalination
}

\author{
Manas Chanda, Amitava Sarkar, Jayant M. Modak \\ Department of Chemical Engineering, Indian Institute of Science, Bangalore 560012, India
}

Received 2 December 2003; accepted 29 January 2004

DOI 10.1002/app.20521

Published online in Wiley InterScience (www.interscience.wiley.com).

\begin{abstract}
A commercial acrylic fiber containing 92 wt \% acrylonitrile was hydrolyzed to convert a part of its nitrile $(-\mathrm{CN})$ groups to carboxylic acid $(-\mathrm{COOH})$ groups and then was coated chemically with $80 \%$ ethoxylated polyethylenimine (EPEI) resin, followed by crosslinking with glutaraldehyde. The resulting sorbent, PAN $\left(\mathrm{CO}_{2} \mathrm{H}\right)($ EPEI.XG), containing carboxylic acid groups and weakly basic tertiary amine groups in close proximity on the same fiber is found to simulate the well-known Sirotherm ${ }^{\mathrm{TM}}$ resins used for partial desalination of brine solution by adsorbing the salt at ambient temperature and desorbing it at an elevated temperature in the same solution. The sorption behavior of the new sorbent was evaluated for solutes $\mathrm{NaCl}$ and $\mathrm{MgCl}_{2}$, showing saturation capacities of 0.797 and $0.877 \mathrm{meq} / \mathrm{g}$ (dry) sorbent fiber, respectively, at $30^{\circ} \mathrm{C}$. The equilibrium sorption data show good agreement with both Langmuir
\end{abstract}

and Freundlich isotherms for sorption from single-component solutions and with Butler-Ockrent and LeVan-Vermeulen models for bicomponent sorption. Although the equilibrium uptake of $\mathrm{NaCl}$ reaches maximum in neutral solutions $(\mathrm{pH} \sim 6.5)$, falling at both lower and higher $\mathrm{pH}$, that of $\mathrm{MgCl}_{2}$ is augmented in alkaline $\mathrm{pH}$ due to additional sorption by cation exchange at the ionic sites formed at higher $\mathrm{pH}$. The initial uptake of the salt, which is nearly instantaneous, exceeds the sorption value attainable at equilibrium. The high initial rate of salt uptake fits a shell-core kinetic model for sorption on fiber of cylindrical geometry. (c) 2004 Wiley Periodicals, Inc. J Appl Polym Sci 93: 883-893, 2004

Key words: desalination; ion-exchangers; resins; adsorption; sorbent fabric; Sirotherm process

\section{INTRODUCTION}

Salinity being one of the most common types of water pollution in the world, the importance of a process for low-cost desalination cannot be overemphasized. The process, designated the Sirotherm process, ${ }^{1}$ uses heat rather than costly chemicals and thus has the obvious advantage of lower operating costs, besides adding no chemical load to the effluent. However, unlike the conventional ion-exchange processes involving chemical regeneration, the Sirotherm process with thermal regeneration is suitable only for partial removal of salts from waters of moderate salinity. In fact, the operating capacity of the Sirotherm resins restricts the economic upper range of salinities to be treated to between 2000 and $3000 \mathrm{mg} / \mathrm{L}$. This conforms to the treatment needs of effluent from cooling water, the largest volume industrial waste effluent. (Industrial and cooling effluents are usually recycled until a dis-

Correspondence to: M. Chanda (chanda@chemeng.iisc. ernet.in).

Contract grant sponsor: Council of Scientific and Industrial Research, New Delhi.

Journal of Applied Polymer Science, Vol. 93, 883-893 (2004) (C) 2004 Wiley Periodicals, Inc. solved salt level of $1000-3000 \mathrm{mg} / \mathrm{L}$ is reached, beyond which a salt bleed from the system becomes necessary.)

The Sirotherm process uses a mixed bed of weakly basic and weakly acidic ion-exchange resins or resins containing both weak acid and weak base functionality within the bead for the adsorption of salts from an aqueous solution in a thermally variable manner. Representing the acidic resin by $\mathrm{R}_{\mathrm{A}} \mathrm{H}$ and the basic resin by $R_{B}$, the following equilibrium may be written for such a system:

$$
\mathrm{R}_{\mathrm{A}} \mathrm{H}+\mathrm{R}_{\mathrm{B}}+\mathrm{NaCl} \rightleftharpoons \mathrm{R}_{\mathrm{A}} \mathrm{Na}+\mathrm{R}_{\mathrm{B}} \cdot \mathrm{HCl}
$$

The Sirotherm process is based on the fact that the equilibrium of eq. (1) is dependent on temperature, the forward reaction being favored at lower temperature to allow salt uptake, and the reverse reaction is favored at a higher temperature so that salt is released when the mixed bed is heated. The difference between the amount of salt retained by the resin hot and cold defines the effective capacity of the resin.

Unlike the following equilibrium of a conventional mixed-bed system using strong-electrolyte type resins: 


$$
\mathrm{R}_{\mathrm{A}} \mathrm{H}+\mathrm{R}_{\mathrm{B}} \mathrm{OH}+\mathrm{NaCl} \rightleftharpoons \mathrm{R}_{\mathrm{A}} \mathrm{Na}+\mathrm{R}_{\mathrm{B}} \mathrm{Cl}+\mathrm{H}_{2} \mathrm{O}
$$

in which the resins are fully ionized and the equilibrium proceeds completely to the right, the hydrolysis of resin salts $\mathrm{R}_{\mathrm{A}} \mathrm{Na}$ and $\mathrm{R}_{\mathrm{B}} \cdot \mathrm{HCl}$ in (1) maintains an appreciable concentration of $\mathrm{Na}^{+}$and $\mathrm{Cl}^{-}$in the solution, so that a high quality of deionized water cannot be produced with a mixed bed of weak resins. However, in many applications, such high-quality water is not necessary and the less favorable equilibrium (1) then becomes an advantage for the Sirotherm process.

The equilibrium of eq. (1) is influenced by many factors, a detailed knowledge of which is necessary for efficient operation of the process. A large number of weak acid and weak base resins being available, selection of an optimum resin pair is difficult. Such selection can be simplified if the titration curves of the individual resins at different temperatures are determined independently of a mixedbed system. In fact, the effectiveness of a resin pair for the Sirotherm process can be assessed from the extent of overlap of the titration curves of the resins. Maximum overlap would occur with two resins of appropriate acid and base strength and possessing plateau-type titration curves. Weiss et al. ${ }^{2}$ devised a screening procedure, which uses titration curve data at 20 and $80^{\circ} \mathrm{C}$ and allows for the effect of $\mathrm{pH}$ and resin ratio, for selecting resin combinations for the Sirotherm process. Thus, in a $0.030 M$ salt solution, the "effective capacity" (i.e., the difference between salt uptake at 20 and $80^{\circ} \mathrm{C}$ ) of the commercial resins was found to be greatest for a poly(vinylbenzyl diethylamine) (PVBDEA) resin in combination with a poly(acrylic acid) resin. Later, polyallylamines were found ${ }^{3}$ to have even higher capacities than PVBDEA.

Composite resin beads were produced by binding together both the acidic and the basic micro-ion exchangers within a permeable matrix. ${ }^{2}$ The capacity of the composite beads is slightly greater than that of the original mixed bed systems (1-1.4 meq/ g). Although these capacities are lower than in chemically regenerated strong-electrolyte type systems, they do refer to the simultaneous removal of both cations and anions.

The rates of sorption by the commercial Sirotherm resins are quite slow in comparison with permanently charged strong electrolyte resins. The rate increases markedly on reducing the particle size. Thus, if resin particles $10-20 \mu \mathrm{m}$ in size are used instead of the conventional 300-1200 $\mu \mathrm{m}$ particles, the half-time for salt uptake is reduced by two orders of magnitude. ${ }^{4}$ However, several mechanical problems arise in han- dling such fine particles, such as excessive pressure drop and difficulties of cleaning the resin bed normally done by backwashing.

Slow kinetics is one of the more important factors that have prevented large-scale industrial applications of the ion-exchange method of separation. Research efforts were therefore directed at developing sorbents of significantly faster kinetics. Shell-functionalization is a common approach used by several workers to overcome the problem of slow kinetics arising from the relative inaccessibility of sorption sites in the interior of resin beads. Different methods were used to prepare shell-functionalized sorbents. In one method reported by Harris, ${ }^{5}$ monomers are polymerized on crosslinked polymer particles, followed by functionalization of the outer polymeric shell.

To greatly enhance the sorption kinetics, a novel process of shell-functionalization of fiber or fabric was developed by Chanda and Rempel. ${ }^{6}$ In this process, polyethylenimine (PEI) was gel-coated as a thin layer on polyacrylonitrile (PAN) fiber/fabric. The gel-coating was preceded by partial hydrolysis of the PAN fiber to generate a limited amount of carboxylic acid functionality (as sodium salt) on the surface and loading $\mathrm{Cu}$ (II) ions, which function as a host ligand to anchor the PEI, followed by crosslinking the surfacecoated PEI with glutaraldehyde and removing the $\mathrm{Cu}$ (II) subsequently by leaching. Later, the process was further simplified ${ }^{7}$ to directly coat PEI on the partially hydrolyzed PAN fiber (in acid form), without $\mathrm{Cu}$ (II) mediation, by heating the fiber in alcoholic solution of PEI, followed by crosslinking with glutaraldehyde.

While the fiber-coated sorbent made by the aforesaid process exhibits the capacity for rapid uptake of heavy metal ions from water, we decided to investigate the possibility of using it for demineralization by the Sirotherm process in view of the fact that the gel-coated fiber contains carboxylic and amine functionalities in close proximity on the same substrate and, being in the form of fiber, it, moreover, offers the prospect of faster kinetics. This sorbent, designated as PAN $\left(\mathrm{CO}_{2} \mathrm{H}\right)(\mathrm{PEI} . \mathrm{XG})$, was, however, found to have insignificant salt uptake capacity, but a similar sorbent, PAN $\left(\mathrm{CO}_{2} \mathrm{H}\right)$ (EPEI.XG), prepared by gel-coating $80 \%$ ethoxylated polyethylenimine (EPEI) (I) on partially hydrolyzed fiber PAN $\left(\mathrm{CO}_{2} \mathrm{H}\right)$ was found to be effective for removing salts from water by the Sirotherm process. This may be explained by the presence of a significantly larger number of tertiary amine groups in EPEI as compared to PEI. In combination with carboxylic acid, tertiary amines are reported ${ }^{1}$ to have higher salt uptake capacity than primary and secondary amines. 


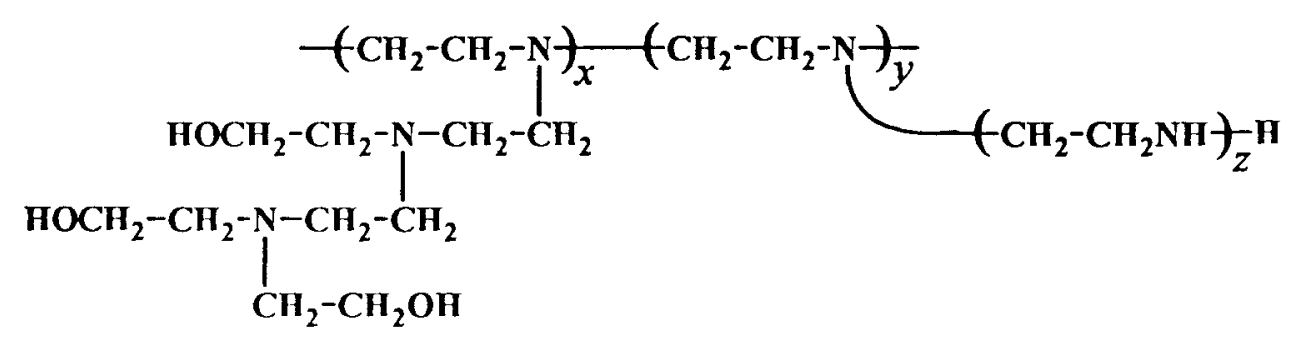

(I)

Unlike the conventional Sirotherm sorbent that consists of weak base and weak acid particulate resins, the present work reports the development of a fibrous analogue of the Sirotherm sorbent which has both weak acid and weak base components bound to the same acrylic fiber. The equilibrium sorption characteristics of this new sorbent were determined as a function of solution concentration, $\mathrm{pH}$, and temperature and its sorption kinetic behavior was studied, using $\mathrm{NaCl}$ and $\mathrm{MgCl}_{2}$ as solutes in dilute solution.

\section{EXPERIMENTAL}

\section{Materials}

The resin used for making the gel-coated sorbent was a $80 \%$ EPEI of equivalent weight of $78 \mathrm{~g}$, obtained as 37 wt \% solution in water from Aldrich, Milwaukee, WI (Cat. No. 30618-5). Poly(acrylic acid) powder $\left(\bar{M}_{w}\right.$ 2000) used for making titration curves was also from Aldrich (Cat. No. 32366-7). Textile-grade acrylic fiber (henceforth simply referred to as PAN fiber), Cashmilon $^{\mathrm{TM}}$, of composition (by wt.) acrylonitrile, 92\%; methyl acrylate, $6 \%$; and sodium methallyl sulfonate, $2 \%$, was obtained from Indian Petrochemical Corp. Ltd. (Baroda, Gujrat, India).

\section{Titration curves}

Titration curves are obtained by measuring the $\mathrm{pH}$ of the aqueous solution of the base or acid resin as acid or alkali is added in small amounts during the course of titration. The amount of acid or alkali added is expressed as a fraction of the total capacity of the resin and is referred to as the "ionization fraction" of the resin. In a typical experiment, $0.10 \mathrm{~N} \mathrm{HCl}$ was added in small amounts from a burette to a $0.10 \mathrm{~N}$ solution of EPEI in $0.10 \mathrm{M} \mathrm{NaCl}$ with continuous stirring at $30^{\circ} \mathrm{C}$ and the $\mathrm{pH}$ of the solution after each addition was measured. The measurements were then repeated with the temperature of EPEI solution raised to $80^{\circ} \mathrm{C}$. Both sets of data were plotted as $\mathrm{pH}$ versus ionization fraction in Figure 1. Similar measurements were made for $0.10 \mathrm{~N}$ solution of poly(acrylic acid) (PAA) in $0.10 \mathrm{M}$ $\mathrm{NaCl}$ solution, which was titrated with $0.10 \mathrm{~N} \mathrm{NaOH}$ at 30 and $80^{\circ} \mathrm{C}$. These data also are presented in Figure
1 , showing $\mathrm{pH}$ of the solution versus ionization fraction.

\section{Sorbent}

The procedure for gel-coating the PAN fiber with EPEI is shown schematically in Figure 2. The nitrile groups on the fiber were partially converted to $-\mathrm{CO}_{2} \mathrm{Na}$ groups by treatment with boiling ethanolic $\mathrm{NaOH}$ under reflux for $10 \mathrm{~h}$ (Step 1). The treated fiber was washed with methanol to remove free alkali.

In Step 2, the partially hydrolyzed PAN fiber, designated as $\mathrm{PAN}\left(\mathrm{CO}_{2} \mathrm{Na}\right)$, was treated twice with an excess of $1 \mathrm{~N} \mathrm{HCl}$ in methanol at room temperature with gentle shaking on a mechanical shaker for a total period of $8 \mathrm{~h}$ to convert the fiber into free acid (- $\mathrm{COOH}$ ) form. In Step 3, the fiber was added to $2 \%$ $(\mathrm{w} / \mathrm{v})$ EPEI resin solution in methanol and refluxed for $10 \mathrm{~h}$. The resulting EPEI-coated PAN fiber was washed with methanol to remove the free resin and then treated with $5 \%(\mathrm{w} / \mathrm{v})$ methanolic solution of

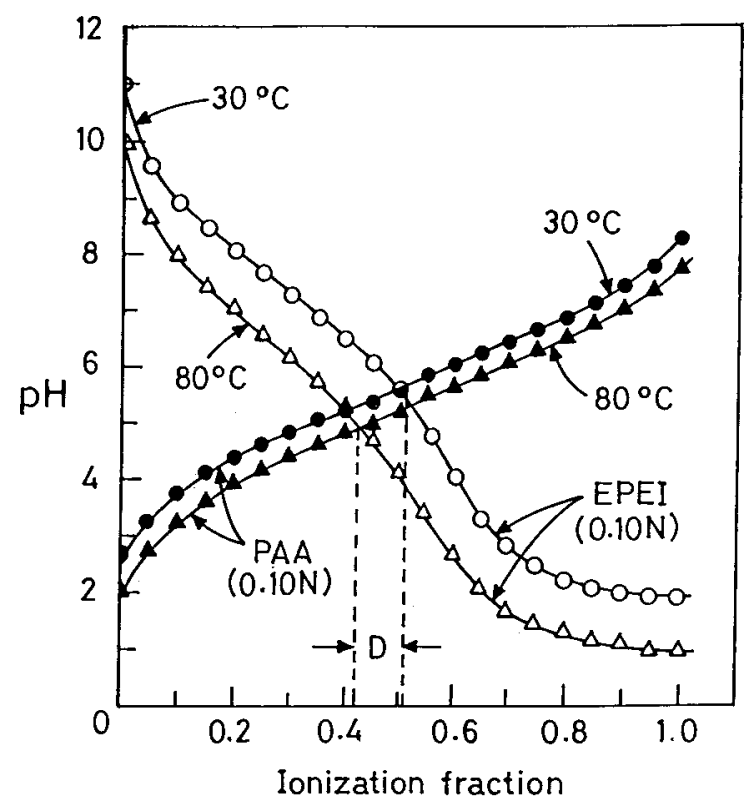

Figure 1 Matching of titration curves for $80 \%$ ethoxylated polyethylenimine (EPEI) and polyacrylic acid (PAA) in $0.10 \mathrm{M} \mathrm{NaCl}$ solution at 30 and $80^{\circ} \mathrm{C}$. 


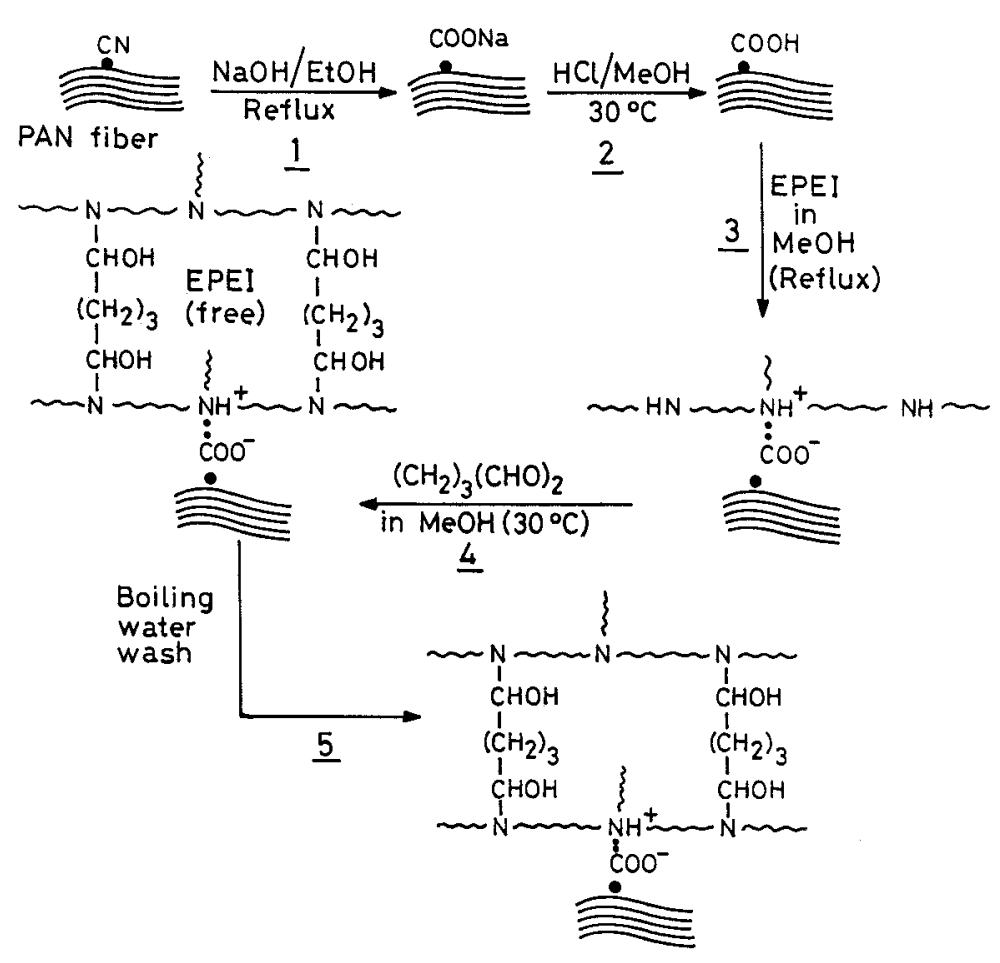

Figure 2 Schematic of the method of preparation of PAN $\left(\mathrm{CO}_{2} \mathrm{H}\right)($ EPEI.XG) by gel-coating and crosslinking of $80 \%$ ethoxylated polyethylenimine (EPEI) on partially hydrolyzed polyacrylonitrile fiber (PAN).

glutaraldehyde for $6 \mathrm{~h}$ for crosslinking (gel-formation) and insolubilization of the EPEI resin (Step 4). The gel-coated fiber was kept in boiling water for $4 \mathrm{~h}$ to remove any residual free EPEI resin (Step 5). The fiber was finally washed with methanol and dried in an air oven at $70^{\circ} \mathrm{C}$. This fibrous sorbent is designated as $\operatorname{PAN}\left(\mathrm{CO}_{2} \mathrm{H}\right)$ (EPEI.XG).

The proton capacity of PAN $\left(\mathrm{CO}_{2} \mathrm{H}\right)($ EPEI.XG), measured in $0.10 \mathrm{~N} \mathrm{HCl}$, is $2.3 \mathrm{meq} / \mathrm{g}$ (dry), which indicates a resin coating of $\sim 18 \%$ by weight, since the measured equivalent weight of EPEI is $78 \mathrm{~g}$. The carboxylate content of the sorbent, estimated by measuring the uptake of $\mathrm{NaOH}$ in $0.10 \mathrm{~N} \mathrm{NaOH}$ solution, is $1.7 \mathrm{meq} / \mathrm{g}$ (dry) sorbent. The sorbent thus has an amine/carboxylic ratio of 1.3, indicating the presence of excess amine over carboxylic acid groups.

The elemental composition (Table I) of the sorbent

TABLE I

Comparison of Elemental Compositions of Polyacrylonitrile Fiber (PAN), Partially Hydrolyzed Fiber PAN $\left(\mathrm{CO}_{2} \mathrm{H}\right)$, and Gel-Coated Fibrous Sorbent $\operatorname{PAN}\left(\mathrm{CO}_{2} \mathrm{H}\right)($ EPEI.XG)

\begin{tabular}{lcccc}
\hline \multirow{2}{*}{\multicolumn{1}{c}{ Sample }} & \multicolumn{4}{c}{ Elemental composition, \% (w/w) } \\
\cline { 2 - 5 } & $\mathrm{C}$ & $\mathrm{H}$ & $\mathrm{N}$ & $\mathrm{O}$ \\
\hline PAN & 66.1 & 5.8 & 23.7 & 2.1 \\
PAN $\left(\mathrm{CO}_{2} \mathrm{H}\right)$ & 65.6 & 5.7 & 22.5 & 5.2 \\
PAN $\left(\mathrm{CO}_{2} \mathrm{H}\right)($ EPEI.XG) & 64.0 & 6.1 & 20.3 & 7.2 \\
\hline
\end{tabular}

PAN $\left(\mathrm{CO}_{2} \mathrm{H}\right)($ EPEI.XG), as compared to that of PAN $\left(\mathrm{CO}_{2} \mathrm{H}\right)$, shows an increase in oxygen content due to the coating of EPEI.XG (glutaraldehyde crosslinked resin) in the former, while the IR spectrum, shown in Figure 3, confirms the presence of amine groups. The nitrogen content $(21.2 \% \mathrm{w} / \mathrm{w})$ of the sorbent, calculated on the basis of $18 \%$ resin coating, is in good agreement with the nitrogen content (20.7\%) determined by elemental analysis (Table I). The properties of PAN $\left(\mathrm{CO}_{2} \mathrm{H}\right)($ EPEI.XG) sorbent are recorded in Table II.

\section{Analysis}

The concentration of sodium chloride was determined by measuring the $\mathrm{Cl}^{-}$concentration, because $\left[\mathrm{Na}^{+}\right]$ $=\left[\mathrm{Cl}^{-}\right]$, when no other salt is present in the solution. The well-known Volhard's method ${ }^{8}$ was used for $\mathrm{Cl}^{-}$ estimation. The concentration of $\mathrm{Mg}^{2+}$ in $\mathrm{MgCl}_{2}$ solution in the absence of other salts was measured by the volumetric analysis by using the EDTA method. The concentration of both $\mathrm{Na}^{+}$and $\mathrm{Mg}^{2+}$ in bicomponent solutions were measured by atomic absorption spectrometry.

\section{Sorption experiments}

Sorption measurements were made with $\mathrm{PAN}\left(\mathrm{CO}_{2} \mathrm{H}\right)$ (EPEI.XG) by using $\mathrm{NaCl}$ and $\mathrm{MgCl}_{2}$ as test sorbates, 


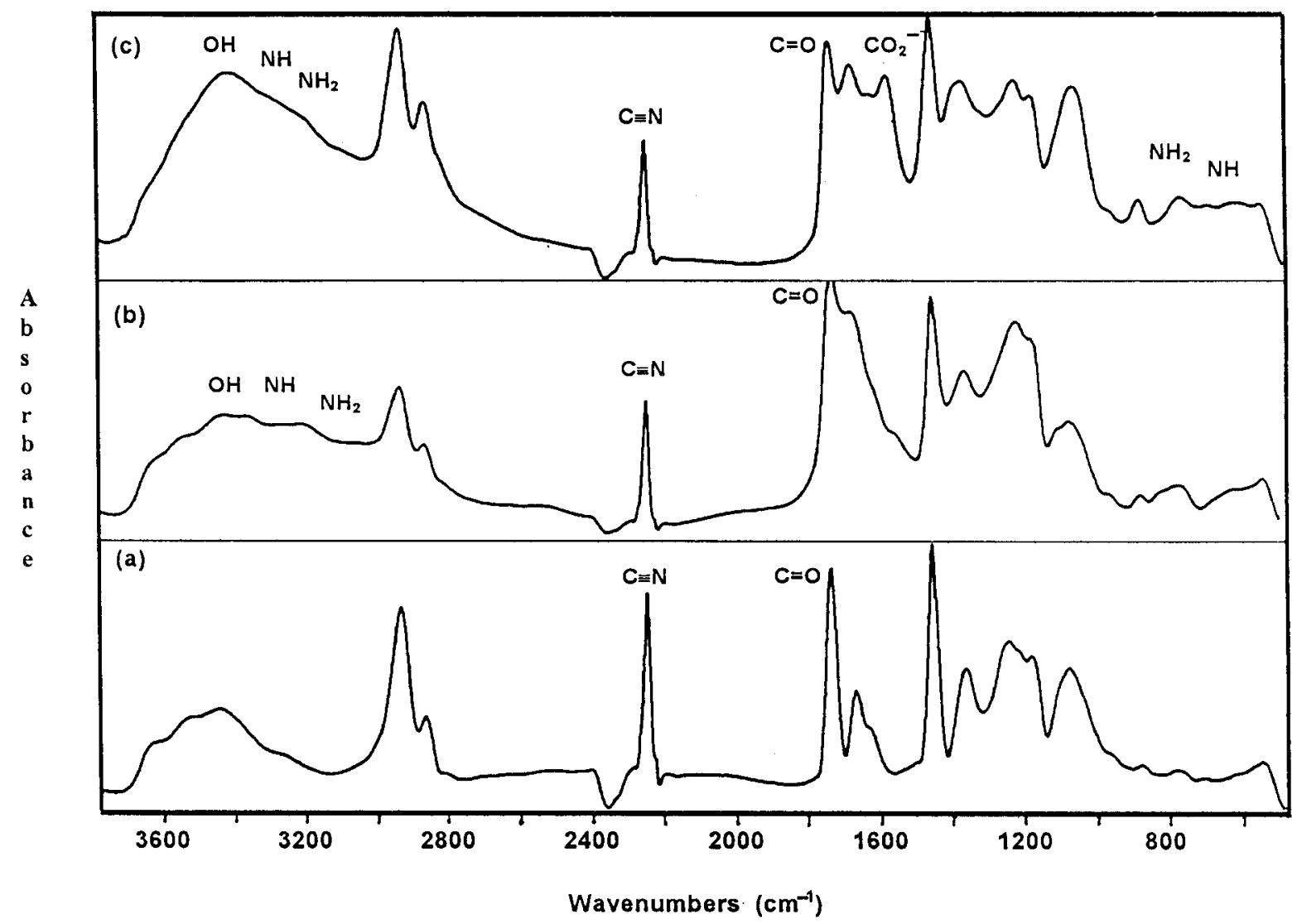

Figure 3 Comparison of FTIR spectra of (a) textile-grade polyacrylonitrile fiber (Cashmilon) PAN, (b) partially hydrolyzed fiber PAN $\left(\mathrm{CO}_{2} \mathrm{H}\right)$, and (c) gel-coated fiber PAN $\left(\mathrm{CO}_{2} \mathrm{H}\right)($ EPEI.XG).

in both single-component and binary solutions. For equilibrium sorption measurements, a small-scale dynamic contact between the sorbent fibers cut into small pieces and the sorbate solution of specified composition was effected in tightly stoppered flasks at $30^{\circ} \mathrm{C}$ on a mechanical shaker for $10 \mathrm{~h}$. The extent of sorption was calculated from the residual concentration of the sorbate in the equilibrated solution. A range of concentrations of the sorbates, $\mathrm{NaCl}$ and $\mathrm{MgCl}_{2}$, in both single-component and bicomponent solutions were employed. The sorption of $\mathrm{NaCl}$ and $\mathrm{MgCl}_{2}$ in single-component solutions was measured at different $\mathrm{pH}$ values of the substrate.

For determination of sorption kinetics, PAN $\left(\mathrm{CO}_{2} \mathrm{H}\right)($ EPEI.XG) fiber, cut into 15-mm-long

TABLE II

Properties of Gel-Coated Sorbent Fiber PAN $\left(\mathrm{CO}_{2} \mathrm{H}\right)($ EPEI.XG) Used for Desalination Study

$\begin{array}{ll}\text { Water content } & 5 \%(\mathrm{w} / \mathrm{w}) \\ \text { Fiber diameter (average) } & 20 \mu \mathrm{m} \\ \text { Fiber length } & 1.5 \mathrm{~cm} \\ \text { BET surface area } & 1.2 \mathrm{~m}^{2} / \mathrm{g} \text { dry } \\ \text { Pore volume } & 0.51 \mathrm{~cm}^{3} / \mathrm{g} \text { dry } \\ \text { Proton capacity } & 2.30 \mathrm{meq} / \mathrm{g} \text { dry }\end{array}$

strands, was used. A rectangular basket made of polypropylene screen $(0.60 \mathrm{~mm}$ opening) was used to hold the sorbents. The basket was fitted to the shaft of a rotor and rotated, while the sorbate solution was brought into contact for a specified period. In this way, the sorbent would be instantly separated from the sorbate solution at any desired time.

Sorption rates were always measured at stirring speeds much above the minimum speed above which the kinetic values are not influenced by the degree of agitation, as determined by experimental measurement of sorption rates at different stirring speeds by using a relatively low solution concentration (0.10M).

\section{RESULTS AND DISCUSSION}

\section{Titration curves}

An insight into the Sirotherm process can be obtained from a superposition of the titration curves of weak base and weak acid resins at different temperatures. In Figure 1, the titration curves of EPEI and poly(acrylic acid) resins at room temperature and at $80^{\circ} \mathrm{C}$ in $0.10 \mathrm{M}$ $\mathrm{NaCl}$ solution are superimposed. It can be seen from these plots that the amine resin has a more pronounced effect than the carboxylic acid resin. The 
point of intersection of the titration curves at one temperature represents the resin compositions that correspond to the same $\mathrm{pH}$ value. This point therefore shows the resin composition and $\mathrm{pH}$ value of the solution at the specified temperature. The difference between the projections of the points of intersection of the hot and cold titration curves onto the resin composition axis, represented by the overlap $D$ in Figure 1, indicates that a change in solution composition would occur on heating the resin mixture in the salt solution and hence EPEI resin in combination with a carboxylic resin could be expected to show an effective salt sorption by the Sirotherm process. A greater overlapping of the hot and cold acid and base titration curves would imply a higher effective capacity.

\section{Single-component sorption isotherm}

The equilibrium data of single-component sorptions of $\mathrm{NaCl}$ and $\mathrm{MgCl}_{2}$ from their respective solutions in water on PAN $\left(\mathrm{CO}_{2} \mathrm{H}\right)\left(\right.$ EPEI.XG) at $30^{\circ} \mathrm{C}$ are plotted in Figures 4 and 5, respectively. Because no measurable sorption of $\mathrm{NaCl}$ is observed on $\mathrm{PAN}\left(\mathrm{CO}_{2} \mathrm{H}\right)$ (PEI.XG) containing gel-coated (crosslinked) polyethylenimine (PEI.XG), the sorption of $\mathrm{NaCl}$ on $\mathrm{PAN}\left(\mathrm{CO}_{2} \mathrm{H}\right)$ -

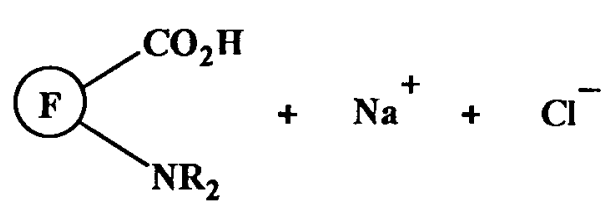

where $\circledast$ represents PAN fiber. The sorption of $\mathrm{MgCl}_{2}$ is similarly represented by

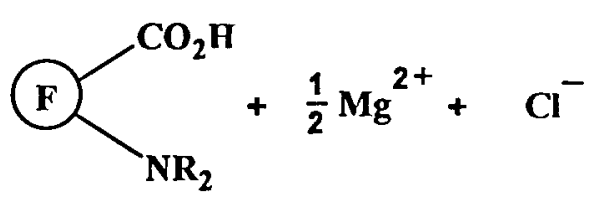

All the equilibrium sorption data of $\mathrm{NaCl}$ and $\mathrm{MgCl}_{2}$ on PAN $\left(\mathrm{CO}_{2} \mathrm{H}\right)($ EPEI.XG) fitted well to both Langmuir and Freundlich isotherms, although the latter gave a somewhat better fit. Defining the parameters $A_{s}$ and $K_{b}$ as the saturation sorption capacity (meq/g dry sorbent) and sorption binding constant ( $\mathrm{L} / \mathrm{meq})$, respectively, the Langmuir isotherm is written as

$$
x^{*}=\frac{K_{b} A_{s} C^{*}}{1+K_{b} C^{*}}
$$

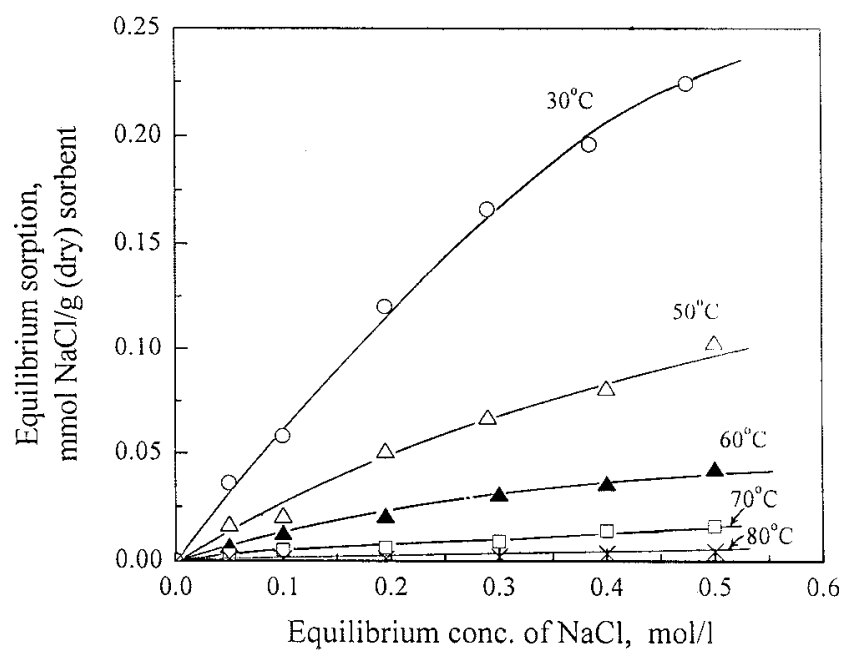

Figure 4 Equilibrium sorption isotherms for $\mathrm{NaCl}$ on gelcoated fibrous sorbent PAN $\left(\mathrm{CO}_{2} \mathrm{H}\right)($ EPEI.XG) at different temperatures in the range $30-80^{\circ} \mathrm{C}$. Sorbent loading: $40 \mathrm{~g}$ (dry)/L; feed solution pH:6.0.

(EPEI.XG) can be attributed to the tertiary amine groups in combination with the carboxylic acid functionality of the partially hydrolyzed PAN fiber and represented by the reaction
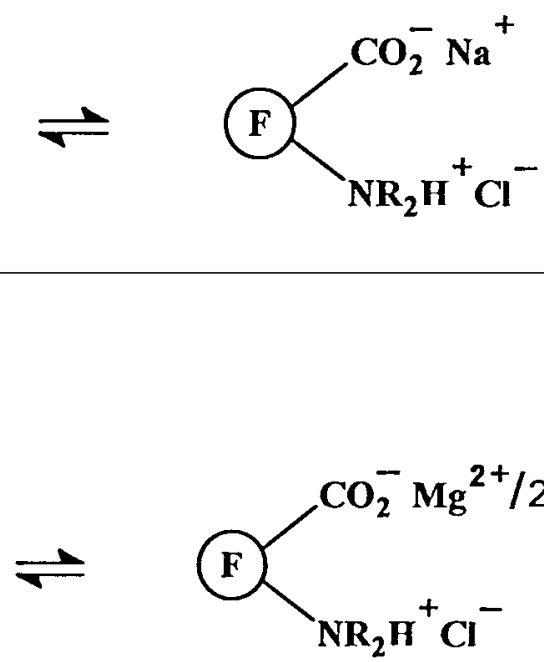

where $x^{*}$ is the equilibrium sorption (meq/g dry sorbent) and $C^{*}$ is the equilibrium sorbate concentration (meq/L) in solution.

The Freundlich isotherm is written as

$$
x^{*}=p\left(C^{*}\right)^{n}
$$

where $p$ and $n$ are parameters, and $x^{*}$ and $C^{*}$ are as defined above.

The values of $A_{s}, K_{b}, p$, and $n$ determined by leastsquares fit of the sorption data in Figures 4 and 5 are 


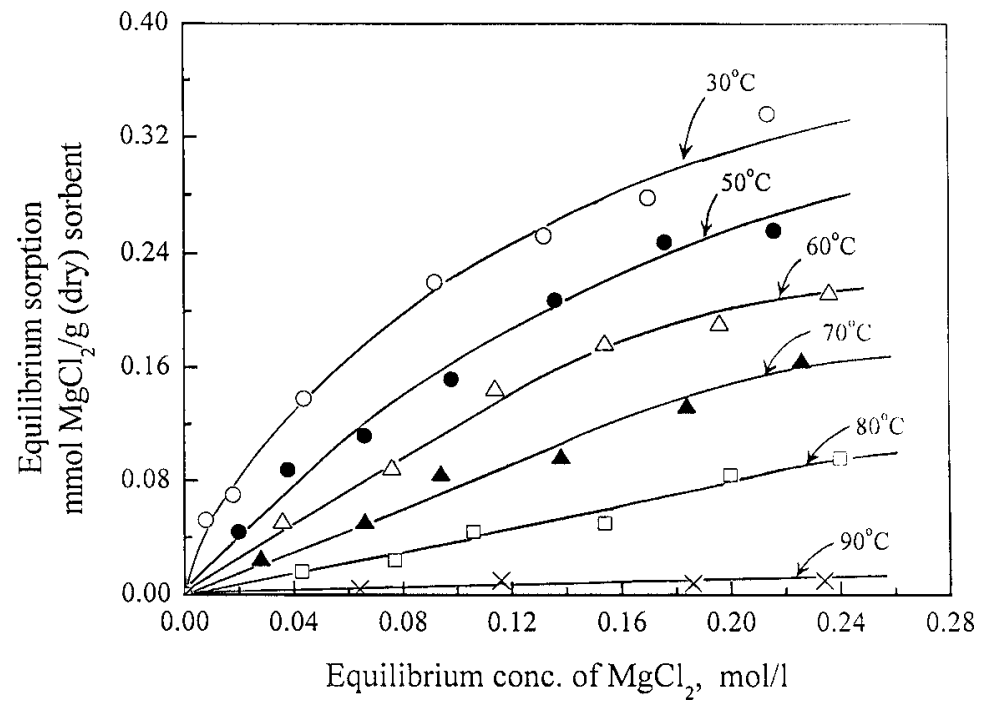

Figure 5 Equilibrium sorption isotherms for $\mathrm{MgCl}_{2}$ on gel-coated fibrous sorbent $\mathrm{PAN}\left(\mathrm{CO}{ }_{2} \mathrm{H}\right)(\mathrm{EPEI}$.XG) at different temperatures in the range $30-90^{\circ} \mathrm{C}$. Sorbent loading: $40 \mathrm{~g}$ (dry)/L; feed solution $\mathrm{pH}: 6.0$.

presented in Table III. A comparison of the values reveals that the saturation capacities of the sorbent for $\mathrm{NaCl}$ and $\mathrm{MgCl}_{2}$ are similar, indicating that possibly the same sites are involved in the sorption process. However, $\mathrm{MgCl}_{2}$ has a much higher bonding constant $\left(K_{b}\right)$ as also a lower value of the Freundlich parameter, $q$, indicating a stronger binding than $\mathrm{NaCl}$ on the gel-coated sorbent.

The equilibrium sorption data for $\mathrm{NaCl}$ and $\mathrm{MgCl}_{2}$ at higher temperatures are also plotted in Figures 4 and 5 , respectively. It is seen that the sorption decreases at higher temperatures, which means that sorption and desorption can take place reversibly in successive cold and hot cycles. Simply the feed solution heated to a higher temperature can thus be used as the regenerant, thus avoiding the use of other chemicals for this purpose. The difference between the sorptions at room temperature and a suitable higher temperature then provides the "effective capacity" of the sorbent.

TABLE III

Langmuir and Freundlich Isotherm Parameters for Sorption of $\mathrm{NaCl}$ and $\mathrm{MgCl}_{2}$ on $\mathrm{PAN}\left(\mathrm{CO}_{2} \mathrm{H}\right)(\mathrm{EPEI} . \mathrm{XG})$

\begin{tabular}{lcrc}
\hline & \multicolumn{3}{c}{ Langmuir isotherm, eq. (5) } \\
\cline { 2 - 4 } Sorbate & $A_{s}$ (meq/g dry sorbent) & $k_{b}$ (L/meq) & Corr. coeff. \\
\hline $\mathrm{NaCl}$ & 0.797 & $9 \times 10^{-4}$ & 0.862 \\
$\mathrm{MgCl}_{2}$ & 0.877 & $58 \times 10^{-4}$ & 0.979 \\
\hline
\end{tabular}

Freundlich isotherm, eq. (6)

\begin{tabular}{lrcc}
\cline { 2 - 3 } Sorbate & $p$ & $n$ & Corr. coeff. \\
\hline $\mathrm{NaCl}$ & $1.2 \times 10^{-3}$ & 0.862 & 0.994 \\
$\mathrm{MgCl}_{2}$ & $19.5 \times 10^{-3}$ & 0.584 & 0.996 \\
\hline
\end{tabular}

\section{Binary sorption isotherm}

The equilibrium sorption data for $\operatorname{PAN}\left(\mathrm{CO}_{2} \mathrm{H}\right)$ (EPEI.XG) in binary adsorbate systems of $\mathrm{NaCl}$ and $\mathrm{MgCl}_{2}$ at $30^{\circ} \mathrm{C}$ are presented in Figure 6. The data show that the sorbent removes divalent ions in preference to monovalent ions. Thus, at equivalent equilibrium concentrations of $0.50 \mathrm{eq} / \mathrm{L}, \mathrm{MgCl}_{2}$ sorption is about seven times higher than that of $\mathrm{NaCl}$.

The single-component Langmuir isotherm [eq. (5)] was extended to binary sorption by Butler and Ockrent, ${ }^{9}$ yielding

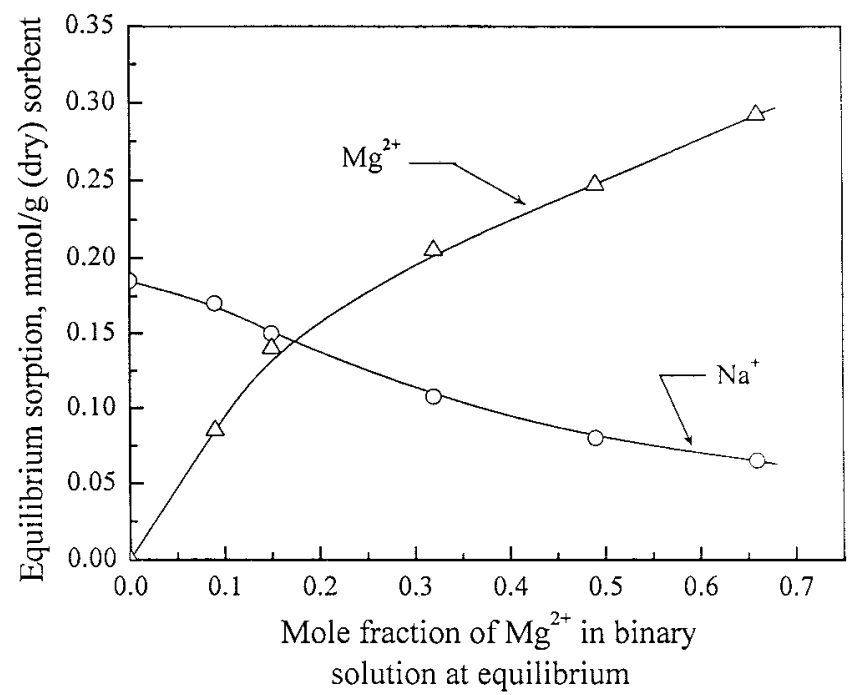

Figure 6 Equilibrium sorption isotherms for $\mathrm{NaCl}$ and $\mathrm{MgCl}_{2}$ in bicomponent solutions on gel-coated fibrous sorbent PAN $\left(\mathrm{CO}_{2} \mathrm{H}\right)\left(\right.$ EPEI.XG) at $30^{\circ} \mathrm{C}$. Sorbent loading: $40 \mathrm{~g}$ (dry)/L; total concentration of $\mathrm{Na}^{+}$and $\mathrm{Mg}^{2+}$ in solution initially: $0.30 \mathrm{~mol} / \mathrm{L}$; feed solution $\mathrm{pH}$; 6.0 . 


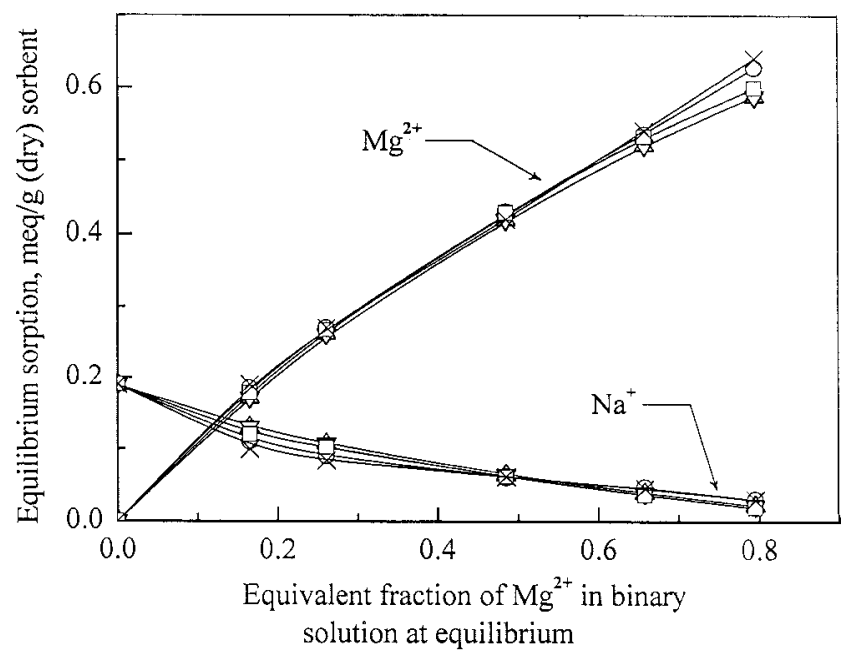

Figure 7 Comparison of experimental sorption values of $\mathrm{NaCl}$ and $\mathrm{MgCl}_{2}$ at $30^{\circ} \mathrm{C}$ with those calculated from different bicomponent sorption models for different compositions of the bicomponent solution. Sorbent loading: $40 \mathrm{~g}$ (dry)/L; total concentration of $\mathrm{Na}^{+}$and $\mathrm{Mg}^{2+}$ in solution initially: $0.30 \mathrm{~mol} / \mathrm{L}$; feed solution $\mathrm{pH}: 6.0$; temperature $30^{\circ} \mathrm{C}$. [O, experimental; $\triangle$, Butler-Ockrent; $\nabla$, Jain-Snoeyink; $\square$, LeVan- Vermeulen (Langmuir); $\quad \times$, LeVan-Vermeulen (Freundlich).]

$$
x_{i}^{*}=\frac{A_{s, i} K_{b, i} C_{i}}{1+K_{b, 1} C_{1}+K_{b, 2} C_{2}} \quad(i=1 \text { or } 2)
$$

Such extension of the Langmuir-like theory is thermodynamically consistent only for the special case where the capacities of the two components are equal. ${ }^{10}$ The above model was modified further by Jain and Snoeyink, ${ }^{11}$ based on the assumption that sorption without competition occurs on some sites when the capacities are not equal and that the number of sites for noncompetitive sorption is proportional to the difference between the maximum loadings of the species [i.e., $\left(A_{s, 1}-A_{s, 2}\right)$, where $A_{s, 1}>A_{s, 2}$ ]. For $A_{s, 2}$ $>A_{s, 1}$, as in the present case, the binary component equations take the form

$$
\begin{gathered}
x_{1}^{*}=\frac{A_{s, 1} K_{b, 1} C_{1}^{*}}{1+K_{b, 1} C_{1}^{*}+K_{b, 2} C_{2}^{*}} \\
x_{2}^{*}=\frac{\left(A_{s, 2}-A_{s, 1}\right) K_{b, 2} C_{2}^{*}}{1+K_{b, 2} C_{2}^{*}}+\frac{A_{s, 1} K_{b, 2} C_{2}^{*}}{1+K_{b, 1} C_{1}^{*}+K_{b, 2} C_{2}^{*}}
\end{gathered}
$$

The first term on the right side of eq. (9) is the Langmuir-like expression for the amount of component 2 that sorbs without competition, while the second term, based on the Langmuir-like model for competitive sorption, represents the amount of component 2 sorbed on the surface in competition with component 1.

The ideal adsorbed solution (IAS) theory, first developed for gaseous mixtures, can also be applied to predict sorption equilibrium for species obeying the pure component equations. The LeVan-Vermeulen model $^{12}$ developed from the IAS theory predicts the equilibrium relationships of solute mixtures from data derived from single-sorption isotherms and is perhaps the simplest isotherm derived from IAS theory. When the capacities of the two components in a bicomponent system are different, the LeVan-Vermeulen model is represented by a Taylor series that converges very rapidly and can be limited in most practical cases to its first two or three terms. The second-order Taylor series approximation of the isotherm for component 1 can be written ${ }^{12}$ as

$$
x_{1}^{*}=\frac{\bar{A}_{s} K_{1}^{*}}{1+K_{1}^{*}+K_{2}^{*}}+\Delta_{L 2}
$$

where $K_{1}^{*}=K_{b, 1} C_{1}^{*}, K_{2}^{*}=K_{b, 2} C_{2}^{*}$, and $\bar{A}_{s}$ is a weighted saturation capacity, given by

$$
\begin{aligned}
\bar{A}_{s}=\frac{A_{s, 1} K_{1}^{*}+A_{s, 2} K_{2}^{*}}{K_{1}^{*}+K_{2}^{*}}+2 \frac{\left(A_{s, 1}-A_{s, 2}\right)^{2}}{A_{s, 1}+A_{s, 2}} \frac{K_{1}^{*} K_{2}^{*}}{\left(K_{1}^{*}+K_{2}^{*}\right)^{2}} \\
\times\left[\left(\frac{1}{K_{1}^{*}+K_{2}^{*}}+\frac{1}{2}\right) \ln \left(1+K_{1}^{*}+K_{2}^{*}\right)-1\right]
\end{aligned}
$$

Furthermore,

$$
\Delta_{L 2}=\left(A_{s, 1}-A_{s, 2}\right) \frac{K_{1}^{*} K_{2}^{*}}{\left(K_{1}^{*}+K_{2}^{*}\right)^{2}} \ln \left(1+K_{1}^{*}+K_{2}^{*}\right)
$$

The isotherm for component 2 can be obtained by interchanging the component subscripts.

As described earlier, the Freundlich isotherm gives a somewhat better fit than the Langmuir isotherm for single-component sorptions. For binary sorption, the

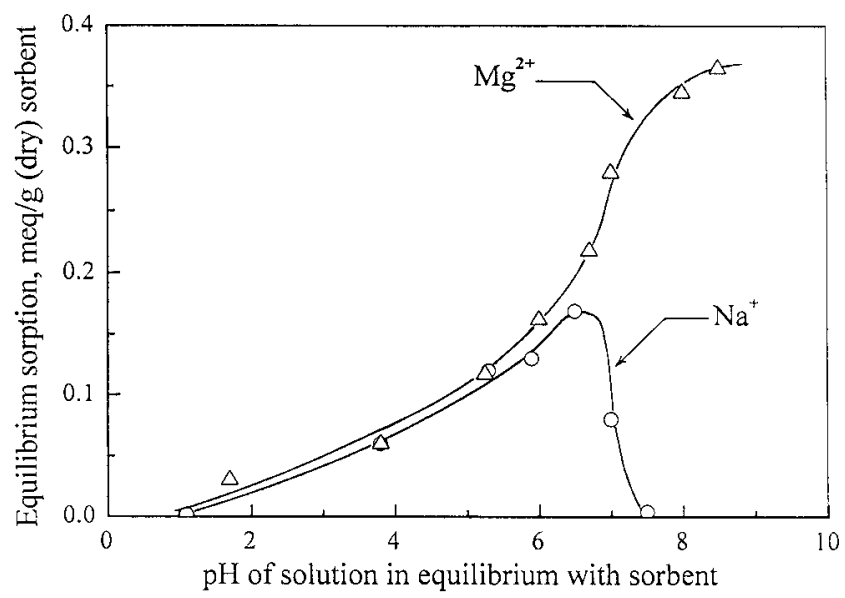

Figure 8 Effect of $\mathrm{pH}$ on sorption of $\mathrm{NaCl}$ and $\mathrm{MgCl}_{2}$ on PAN $\left(\mathrm{CO}_{2} \mathrm{H}\right)$ (EPEI.XG). Other conditions are similar to those given in Figures 5 and 6 , respectively. 
LeVan-Vermeulen procedure yields the following two-term binary Freundlich isotherm ${ }^{12}$ :

$$
x_{1}^{*}=\frac{\bar{n} P_{1}^{*}}{\left(P_{1}^{*}+P_{2}^{*}\right)^{1-\bar{n}}}+\Delta_{F 2}
$$

where $P_{1}^{*}=C_{1}^{*}\left(p_{1} / n_{1}\right)^{1 / n_{1}}, P_{2}^{*}=C_{2}^{*}\left(p_{2} / n_{2}\right)^{1 / n_{2}}$, and $\bar{n}$ is a weighted exponent given by

$$
\bar{n}=\frac{n_{1} P_{1}^{*}+n_{2} P_{2}^{*}}{P_{1}^{*}+P_{2}^{*}}
$$

Furthermore,

$$
\Delta_{F 2}=\left(n_{1}-n_{2}\right) \frac{P_{1}^{*} P_{2}^{*}}{\left(P_{1}^{*}+P_{2}^{*}\right)^{2-\bar{n}}} \ln \left(P_{1}^{*}+P_{2}^{*}\right)
$$

As before, the isotherm for component 2 can be obtained by interchanging component subscripts. The parameters $p_{1}$ and $n_{1}$ are the Freundlich parameters of the single-component isotherm for $\mathrm{NaCl}$ and similarly $p_{2}$ and $n_{2}$ are those for $\mathrm{MgCl}_{2}$.

By using the single-component parameter values as given in Table III, the sorptions of $\mathrm{NaCl}$ and $\mathrm{MgCl}_{2}$ from binary mixtures were computed by using the binary Langmuir and Freundlich isotherms, represented by eqs. (7)-(10) and (13). These are plotted in Figure 7, for comparison with experimentally observed values. All the isotherms are seen to predict binary sorption of $\mathrm{NaCl}$ and $\mathrm{MgCl}_{2}$ reasonably well. This would be expected because the single-component sorption capacities of $\mathrm{NaCl}$ and $\mathrm{MgCl}_{2}$ on the sorbent are quite similar. However, in binary sorptions also, as in single-component sorptions, the Freundlich isotherm provides somewhat better fit than the Langmuir isotherm.

\section{Effect of $\mathrm{pH}$}

The sorbent PAN $\left(\mathrm{CO}_{2} \mathrm{H}\right)($ EPEI.XG) contains both amine and carboxylic acid groups, the ratio of the

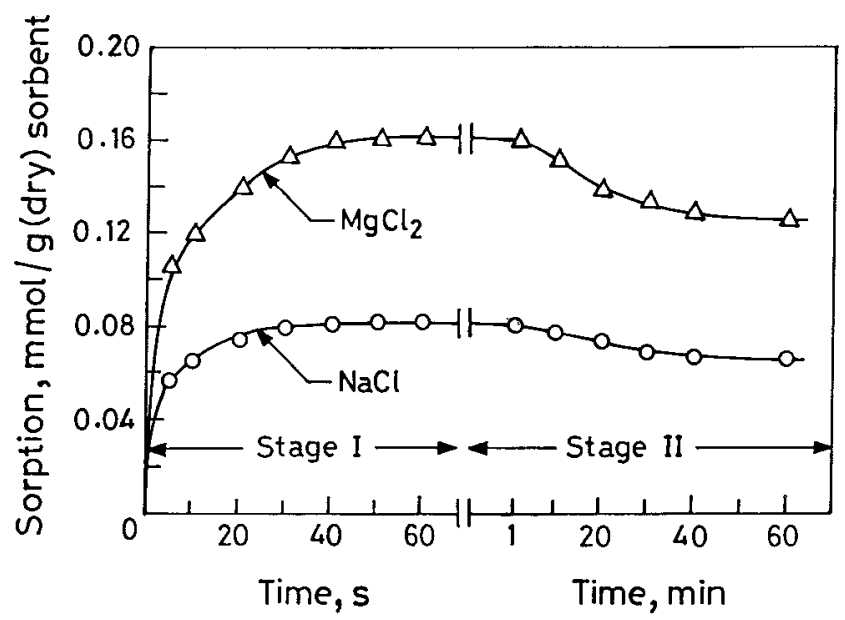

Figure 9 Sorptions of $\mathrm{NaCl}$ and $\mathrm{MgCl}_{2}$ on $\mathrm{PAN}\left(\mathrm{CO}_{2} \mathrm{H}\right)$ (EPEI.XG) in single-component solutions as a function of time. Sorbent loading: $40 \mathrm{~g}$ (dry)/L; feed solution concentration: $0.10 \mathrm{~mol} / \mathrm{L}$; feed solution $\mathrm{pH}$ : 6.0 ; temperature $30^{\circ} \mathrm{C}$.

former to the latter estimated to be 1.3. The sorbent is thus capable of neutralizing some amount of acids and bases. Thus, experimentally it is a $\mathrm{pH}$ change of 5.2 to 7.4 of the equilibrated solution in the presence of $10 \mathrm{wt} \%$ of the sorbent PAN $\left(\mathrm{CO}_{2} \mathrm{H}\right)$ (EPEI.XG). However, even this small change of $\mathrm{pH}$ has a profound effect on the sorption capacity of the sorbent. Thus, as can be seen from Figure 8, the maximum sorption of $\mathrm{Na}^{+}$occurs at $\mathrm{pH} \sim 6.5$, while the sorption falls drastically at both lower and higher $\mathrm{pH}$ values.

The effect of $\mathrm{pH}$ on the sorption of $\mathrm{Mg}^{+}$(Fig 8) is very different from that on $\mathrm{Na}^{+}$sorption, especially in the high $\mathrm{pH}$ range (6-9) where the sorption of $\mathrm{Mg}^{+}$is found to increase sharply, instead of decreasing. This can be attributed to significant contribution to $\mathrm{Mg}^{+}$ sorption by cation exchange at the ionic sites formed at higher $\mathrm{pH}$ :

$$
\text { (F) }-\mathrm{CO}_{2}^{-} \mathrm{NH}_{4}^{+}+\frac{1}{2} \mathrm{Mg}^{2+} \longrightarrow \text { (F) }-\mathrm{CO}_{2}^{-} \mathrm{Mg}^{2+} / 2+\mathrm{NH}_{4}^{+}
$$

\section{Sorption kinetics}

The sorptions of $\mathrm{NaCl}$ and $\mathrm{MgCl}_{2}$ from single-component solutions were measured as a function of time by using a rotational speed (200-300 rpm) of the sorbent basket much above the experimentally determined minimum for elimination of film diffusional resistance. The sorption data plotted in Figure 9 show that the initial sorption rate of $\mathrm{MgCl}_{2}$ is nearly twice that of $\mathrm{NaCl}$. For both $\mathrm{NaCl}$ and $\mathrm{MgCl}_{2}$, the initial sorption is very fast, attaining in a short time a maximum value that is significantly higher than the equilibrium value which is attained eventually. While it takes $30-50 \mathrm{~s}$ to reach the initial maximum, the equilibrium sorption is attained in 40-60 $\mathrm{min}$.

The sorption can be assumed to follow a shell-core scheme only if the process is irreversible and is fast compared to diffusion. While the equilibrium sorption of $\mathrm{NaCl}$ and $\mathrm{MgCl}_{2}$ presumably involves equilibrium ion-exchange reactions, as shown by eqs. (1) and (2), the rapid initial uptake of the sorbates exceeding the respective equilibrium limits may be attributed to 
both physical and chemical adsorptions taking place on the fibrous sorbent. Because this sorption in the initial phase $\mathbf{I}$ is very rapid (reaching maximum within about $40 \mathrm{~s}$ ), it may be assumed to be irreversible during this short period and the sorption in this period may thus be recorded as fractional attainment of the maximum sorption $\left(\bar{X}_{m}\right)$. A shell-core model was earlier derived ${ }^{6}$ for a cylindrical sorbent of very large length/diameter ratio, representing a fiberlike sorbent. The rate of sorption derived from the model is given by

$$
\begin{aligned}
\left(\frac{D \lambda C_{0}}{r_{0}^{2} \bar{C}_{r}}\right) t & =\frac{\ln \beta}{2 \alpha} \ln \left(\frac{\beta^{2}+R^{* 2}}{\beta^{2}+1}\right) \\
& +\sum_{n=1,2, \ldots} \frac{\beta^{2 n}}{4 \alpha n^{2}}\left\{\frac{1}{\left(\beta^{2}+R^{* 2}\right)^{n}}-\frac{1}{\left(\beta^{2}+1\right)^{n}}\right\}
\end{aligned}
$$

where $D$ is the resin diffusivity, $\lambda$ is the molar distribution coefficient, $C_{0}$ is the initial sorbate concentration in solution, $\bar{C}_{r}$ is the sorption capacity per unit volume of unreacted sorbent, $r_{0}$ is the radius of cylindrical sorbent, $R^{*}=$ radial position (dimensionless) of moving boundary, $\alpha$ is the ratio (dimensionless) of sorption on resin at saturation and total amount of sorbate initially in substrate, and

$$
\beta=\left(\frac{1-\alpha}{\alpha}\right)^{1 / 2}
$$

To test the model with experimental sorption data, eq. (17) can be written in terms of fractional sorption $\bar{X}_{m}$ by noting that

$$
R^{*}=\left(1-\bar{X}_{m}\right)^{1 / 2}
$$

Equation (17) combined with eq. (19) can be used to fit the initial phase sorption data to the model. The right-hand side (RHS) of eq. (17) is thus evaluated and plotted against $t$ in Figure 10. As can be seen from this figure, the kinetic data on PAN$\left(\mathrm{CO}_{2} \mathrm{H}\right)($ EPEI.XG) show an approximately linear fit in the initial region extending from 0 to $85 \%$ of the maximum sorption for both $\mathrm{NaCl}$ and $\mathrm{MgCl}_{2}$, which is followed by a sharp deviation. This reflects the fact that, as can be seen from Figure 9, beyond about $85 \%$ of the maximum sorption, the rate falls abruptly, which may be attributed to several factors, the more important among them being the decreasing diffusivity in inner layers of the sorbent fiber.

From the slope of the linear plot in the initial region (Fig. 10), $\lambda D$ was calculated, yielding a value of 1.54 $\times 10^{-8} \mathrm{~cm}^{2} / \mathrm{s}$ for $\mathrm{NaCl}$ and $4.71 \times 10^{-8} \mathrm{~cm}^{2} / \mathrm{s}$ for $\mathrm{MgCl}_{2}$, which are comparable with values for solidphase diffusivity. The high initial sorption rate may

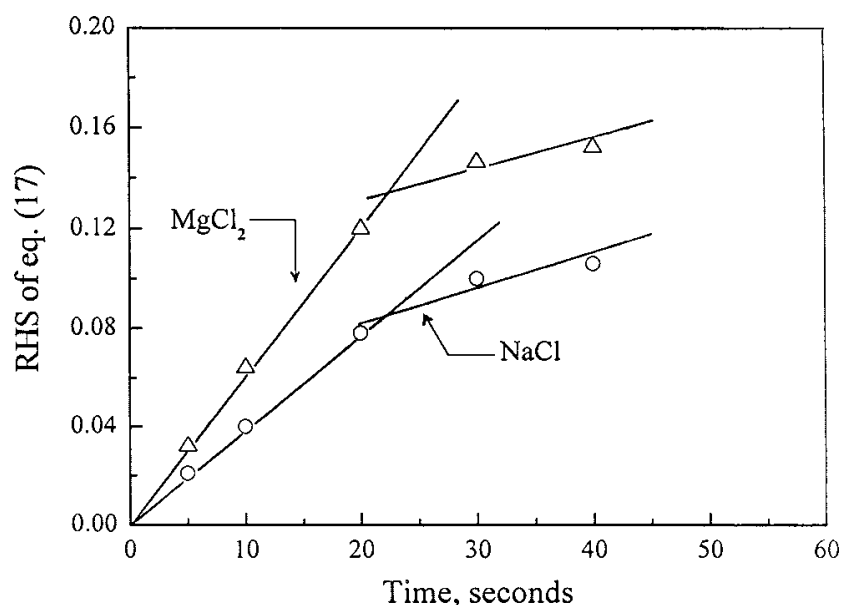

Figure 10 Test of eq. (17) with data of Figure 9 for sorption of $\mathrm{NaCl}$ and $\mathrm{MgCl}_{2}$ on PAN $\left(\mathrm{CO}_{2} \mathrm{H}\right)$ (EPEI.XG) at $30^{\circ} \mathrm{C}$.

thus be attributed to the large exposed surface of the fiber rather than to higher diffusivity.

\section{CONCLUSION}

Ethoxylated polyethylenimine, gel-coated on partially hydrolyzed polyacrylonitrile fiber, $\operatorname{PAN}\left(\mathrm{CO}_{2} \mathrm{H}\right)$ (EPEI.XG), is found to be effective for removal of $\mathrm{NaCl}$ and $\mathrm{MgCl}_{2}$ from water at ambient temperature $\left(30^{\circ} \mathrm{C}\right)$, although similarly gel-coated poyethylenimine is found to be practically ineffective. Because the gelcoated fiber desorbs $\mathrm{NaCl}$ and $\mathrm{MgCl}_{2}$ almost fully at 80 and $90^{\circ} \mathrm{C}$, respectively, PAN $\left(\mathrm{CO}_{2} \mathrm{H}\right)($ EPEI.XG) can be used similar to Sirotherm resins for reducing salinity of water. The extent of desalination is dependent on $\mathrm{pH}$, the maximum removal of $\mathrm{NaCl}$ taking place at neutral $\mathrm{pH}$, while the removal of $\mathrm{MgCl}_{2}$ is augmented further in alkaline $\mathrm{pH}$ due to additional sorption at cation exchange sites generated at higher $\mathrm{pH}$.

The equilibrium data of single-component sorptions fit well to both Langmuir and Freundlich isotherms. Good agreement is obtained between the experimental and predicted sorptions from biocomponent solutions of $\mathrm{NaCl}$ and $\mathrm{MgCl}_{2}$, using the competitive Langmuir-like Butler-Ockrent model, the modified competitive Lamgmuir-like Jain-Snoeyink model, and the LeVan-Vermeulen model. Sorption of both $\mathrm{NaCl}$ and $\mathrm{MgCl}_{2}$ takes place in two phases - Phase I in which the sorption is nearly instantaneous and higher than the equilibrium sorption, and Phase II in which the sorption level decreases and finally attains the equilibrium value. The initial high rate of sorption fits to a shell-core model of sorption on a sorbent of cylindrical geometry. The high rate of salt uptake is attributed to the highly exposed surface of the fiber.

The financial support from the Council of Scientific and Industrial Research, New Delhi, by way of a research grant- 
in-aid (to M.C.) is gratefully acknowledged. We also thank Dr. P. R. Achar, Deputy Manager R\&D, Indian Petrochemicals Corp., Baroda for supplying textile-grade acrylic fabric which facilitated this work.

\section{REFERENCES}

1. Weiss, D. E.; Bolto, B. A.; McNeill, R.; MacPherson, A. S.; Siudak, R. V.; Swinton, E. A.; Willis, D. Aust J Chem 1966, 19, 561.

2. Weiss, D. E.; Bolto, B. A.; McNeill, R.; MacPherson, A. S.; Siudak, R.; Swinton, E. A.; Willis, D. Aust J Chem 1968, 21, 2703.

3. Bolto, B. A.; Eppinger, K.; MacPherson, A. S.; Siudak, R. V.; Weiss, D. E.; Willis, D. Desalination 1973, 13, 269.
4. Bolto, B. A.; MacPherson, A. S.; Siudak, R. V.; Warner, R. E.; Weiss, D. E.; Willis, D. Thermal regeneration of weak electrolyte resins; in Ion Exchange in the Process Industries; Society Chemistry Industry: London, 1970; p. 270.

5. Harris, W. I. Eur. Pat. Appl. EP. 1984, 101, 943 (Cl. c08F237/02).

6. Chanda, M.; Rempel, G. L. Ind Eng Chem Res 2003, 42, 5647.

7. Chanda, M.; Sarkar, A.; Chen, Z. J. Polym Mater 2004, 21, 21.

8. Vogel, A. I. A Textbook of Quantitative Inorganic Analysis; 3rd ed.; ELBS and Longmans Green: London, 1962.

9. Butler, J. A. V.; Ockrent, C. J Phys Chem 1931, 34, 497.

10. Broughton, D. B. Ind Eng Chem 1948, 40(8), 1506.

11. Jain, J. S.; Snoeyink, V. L. J Water Pollut Control Federation 1973, 45(12), 2463.

12. LeVan, M. D.; Vermeulen, T. J Phys Chem 1981, 85, 3247. 